\title{
THE HEATS OF COMBUSTION OF PHENOL AND THE THREE GRESOLS
}

\author{
J. D. Cox \\ National Chemical Laboratory, D.S.I.R., Teddington, Middlesex, U.K.
}

Precise measurements of the thermodynamic properties of phenol and some of its homologues are being made in this Laboratory. As part of this programme, the heats of combustion of phenol and the three cresols (methylphenols) have been accurately determined and are here reported; the heats of combustion of the six xylenols (dimethylphenols) will be reported elsewhere.

The combustion calorimetry of the phenols involves the difficulty that these compounds are somewhat hygroscopic and are prone to oxidation by air or oxygen. Additionally, phenol and its lower homologues, although most are solids at $25^{\circ}$, have vapour pressures at $25^{\circ}$ which are too great to permit their being placed unenclosed within a combustion bomb, when work of high precision is attempted. These problems were all overcome in the present work by sealing pellets of the solid phenols inside polyethylene bags, which were then placed inside the crucible of the combustion bomb. Experiments on $m$-cresol, a viscous liquid at $25^{\circ}$, were also conducted with samples sealed in polyethylene bags, in order to make the conditions of measurement closely comparable with those adopted for the solid phenols.

The polyethylene bags were rectangular $(25 \mathrm{~mm} \times 30 \mathrm{~mm}$; average mass $0.09 \mathrm{~g}$ ), and were made from polyethylene film $0.05 \mathrm{~mm}$ thick. To make the edges of the bag, two surfaces of the film were sealed together by means of a low-temperature soldering iron having a wheel-and-axle bit. Pellets of a solid phenol were prepared in a "dry-box" and were placed inside a weighed open-ended polythene bag; in the case of $m$-cresol, the liquid was pipetted into a weighed bag. The bag was then sealed, and the whole weighed. The bag and contents were placed inside the platinum crucible of the bomb ${ }^{1,2}$, and platinum fuse wire, connected to the bomb's firing circuit, was placed in contact with the top surface of the bag. With this arrangement, passage of a current through the fuse wire always ignited the bag and its contents, no kindling material other than the bag being required.

The general technique used in the combustion experiments has been described $^{\mathbf{1}-3}$. The energy equivalent of the calorimeter was determined electrically, and all temperature measurements were made with a platinum resistance thermometer. The energy of combustion, $\Delta U_{\mathrm{c}}^{\circ}$, of the polyethylene film was measured as $-46427 \pm 9 \mathrm{~J} / \mathrm{g}$. The samples of the phenols used were prepared in this Laboratory; sample purities were determined by a freezing point method and exceeded 99.9 moles per cent in every instance. Mean values for the standard heats of combustion, $\Delta H_{c}^{\circ}$, of phenol and the cresols are summarized in Table 1 . The uncertainties 


\section{J. D. COX}

quoted are standard deviations of the mean and include a small contribution from the uncertainty in the energy equivalent of the calorimeter; the " uncertainty interval" of each value in the table is by definition twice the given standard deviation of the mean.

The literature contains only one modern reference to the heat of combustion of phenol (and none to that of the cresols) which might be compared with the value reported in the table. Thus Parks, Manchester and Vaughan $^{4}$ gave $-730.36 \mathrm{kcal} / \mathrm{mole}$ as $\Delta H_{\mathrm{c}}^{\circ}$ for phenol. The discrepancy between this value and ours falls just outside the sum of the two uncertainty intervals, but as Parks, Manchester and Vaughan's paper contains no experimental details, further comment is not possible.

Table 1. Heats of combustion of phenol and the cresols. "Thermochemical" calories. 1 cal $\equiv 4 \cdot 1840$ abs. J.

\begin{tabular}{|c|c|c|c|c|}
\hline Compound & $\begin{array}{l}\text { State at } \\
25^{\circ}\end{array}$ & $\begin{array}{c}-\Delta H_{\mathrm{c}}^{\circ} \\
(\mathrm{kcal} / \mathrm{mole})\end{array}$ & $\begin{array}{c}-\Delta H_{\mathrm{f}}^{\circ} \\
(\mathrm{kcal} / \mathrm{mole})\end{array}$ & $\begin{array}{c}-\Delta H_{i}^{*} \\
\text { (kcale/mole) }\end{array}$ \\
\hline $\begin{array}{l}\text { Phenol } \\
o \text {-Cresol } \\
m \text {-Cresol } \\
p \text {-Cresol }\end{array}$ & $\begin{array}{l}\text { cryst. } \\
\text { cryst. } \\
\text { liquid } \\
\text { cryst. }\end{array}$ & $\begin{array}{l}729.82 \pm 0.07 \\
882.79 \pm 0.10 \\
885.44 \pm 0.06 \\
884.02 \pm 0.07\end{array}$ & $\begin{array}{l}39 \cdot 44 \\
48 \cdot 84 \\
46 \cdot 19 \\
47 \cdot 61\end{array}$ & $\begin{array}{l}23.03 \pm 0.14 \\
30.67 \pm 0.21 \\
31.44 \pm 0.26 \\
29.94 \pm 0.36\end{array}$ \\
\hline
\end{tabular}

The fourth column of the table contains values of the standard heats of formation from the elements, $\Delta H_{\mathrm{f}}^{\circ}$, as calculated from values of $\Delta H_{\mathrm{c}}^{\circ}$ with the aid of values for the heats of formation of carbon dioxide and water $^{5}$. The last column of the table contains values of the heats of formation of the compounds at $25^{\circ} \mathrm{C}$ in the ideal gas state, $\Delta H_{\mathrm{f}}^{*}$. Strictly, these values refer to the real gases, but the vapour pressures of the compounds at $25^{\circ}$ are sufficiently low for the values to be indistinguishable from those for the ideal gas. Values of the latent heats of sublimation (or latent heat of vaporization for the liquid $m$-cresol), required for the calculation of $\Delta H_{i}^{*}$, were taken from the work of Biddiscombe and Martin ${ }^{6}$ of this Laboratory. These workers made careful measurements of the vapour pressures of phenol and the cresols in the region of $25^{\circ}$, and from their measurements calculated the latent heats of sublimation (or vaporization). The uncertainties quoted in the last column of the table were obtained by combining the standard deviations of the $\Delta H_{\text {o values with }}$ those of the latent heats, assuming that there are no errors in $\Delta H^{\circ}$ for carbon dioxide and water.

With values of $\Delta H_{t}^{*}$ available, the calculation of the resonance energies of phenol and the cresols was attempted by the well-known procedure of calculating the heats of formation from the atoms in their ground states, and comparing the results with values obtained by summing bond energy terms. Calculations were made from values for the heats of atomization of the elements and bond energies taken from three different compilations ${ }^{7-9}$. Similar results were obtained from each compilation, so that it is only necessary to choose one of them for a detailed discussion. The compilation chosen for the present purpose is that of Laidler ${ }^{9}$, which is not only the most recent of the three but also appears to be the most precise. Laidler's bond energy scheme takes account of the various types of $\mathrm{C}-\mathrm{H}$ bonds 
(primary, secondary or tertiary) in the molecule, and also of the types and positions of $\mathrm{C}-\mathrm{H}$ bonds with respect to $\mathrm{C}=\mathrm{G}$ bonds. The resonance energies of phenol and the cresols, when calculated from the present values of $\Delta H_{1}^{*}$ with the aid of Laidler's data, were as follows:

$$
\begin{aligned}
& \text { phenol } 44.7 \mathrm{kcal} / \mathrm{mole} \text {; benzene } 42.8 \mathrm{kcal} / \mathrm{mole} \\
& o \text {-cresol } 44.2 \mathrm{kcal} / \mathrm{mole} \text {; } \\
& m \text {-cresol } 45.0(\mathrm{kcal} / \mathrm{mole}) ; \text { toluene } 42.5 \mathrm{kcal} / \mathrm{mole} \\
& p \text {-cresol } 43.5(\mathrm{kcal} / \mathrm{mole}) .
\end{aligned}
$$

For purposes of comparison, the resonance energies of benzene and toluene, taken from Laidler's paper', have been included in the above table. Considering first phenol relative to benzene, it may be seen that the resonance energy of the former appears to be about $2 \mathrm{kcal} / \mathrm{mole}$ greater than the resonance energy of the latter. Qualitatively, this situation was to be anticipated because the resonance structures of phenol would be expected to include the quinonoid forms (I), (II) and (III):

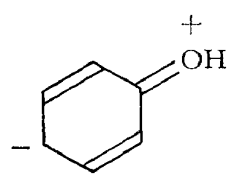

(I)

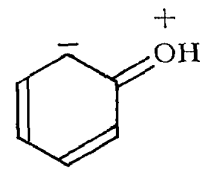

(II)

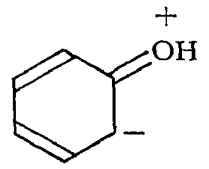

(III)

in addition to the normal Kekule and Dewar forms of the benzene ring. Hitherto, however, heat of formation data for phenol have been insufficiently reliable to show whether or not these resonance forms made a measurable contribution to the resonance energy ${ }^{10}$. It is therefore important to consider carefully whether the apparent $2 \mathrm{kcal} / \mathrm{mole}$ difference between the resonance energies of phenol and benzene is real. Errors in the values of $\Delta H_{\mathrm{t}}^{*}$ for the two compounds are unlikely to exceed $0.5 \mathrm{kcal} / \mathrm{mole}$, but errors greater than this may be involved in the calculation of atomic heats of formation and total bond energies. Fortunately these errors will mainly affect the absolute values of the two resonance energies, rather than their difference, since most of the data used are common to the two calculations. Data which are not common to the two calculations relate to the $\mathrm{C}-\mathrm{OH}$ bond. Laidler" recommends that a "mean" bond energy term of $198.1 \mathrm{kcal}$ be used for the $\mathrm{C}-\mathrm{OH}$ bond; at present, too few reliable values of the heats of formation of aliphatic alcohols exist to permit making a distinction between the $\mathrm{G}-\mathrm{OH}$ bond energies in primary, secondary and tertiary alcohols. From Roberts and Skinner's ${ }^{11}$ summary of bond energy data for alcohols it seems that the mean bond energy for $\mathrm{C}-\mathrm{OH}$ must be considered uncertain to $\pm 2 \mathrm{kcal}$. As this uncertainty is the dominant one in a comparison of phenol with benzene, it may be concluded that the extra resonance stabilization of phenol relative to benzene lies within the limits 0 to $4 \mathrm{kcal} / \mathrm{mole}$. When a more reliable value becomes available for the $\mathrm{C}-\mathrm{OH}$ bond energy term, it should be possible to define the extra resonance stabilization of phenol within closer limits. 


\section{J. D. COX}

If attention is confined to intercomparison of phenol and the cresols, the uncertainty of the $\mathrm{C}-\mathrm{OH}$ bond energy becomes irrelevant. It may then be seen that the resonance energies of phenol and $m$-cresol are indistinguishable within the combined standard errors, whereas the resonance energies of $o$ - and $p$-cresol are slightly less than the resonance energy of $m$-cresol. A parallel to this situation is found in the acidities of these compounds, where phenol and $m$-cresol have closely similar acidities in water ${ }^{12}$, whilst $o$ - and $p$-cresol are appreciably weaker acids. An explanation for the parallel presents itself when it is remembered that the appreciable acidity of phenol may be ascribed ${ }^{10}$ to the contribution of structures (IV), (V) and (VI) to the resonance in the phenolate ion.

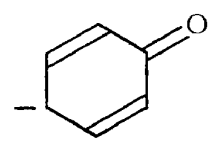

(IV)

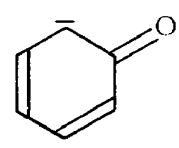

(V)

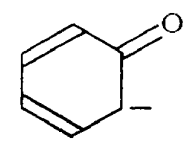

(V'I)

Substitution of a $m$-methyl group into either phenol or phenolate ion would not be expected to influence the contributions of quinonoid structures (I)-(III) or (IV)-(VI). Hence phenol and $m$-cresol should have closely similar resonance energies and acidities. On the other hand, substitution of $o$ - or $p$-methyl groups would be expected to discourage the placing of a negative charge (structures (I)-(III) or (IV)-(VI)) on the carbon atoms to which the methyl groups are attached, i.e. 0 - and $p$-cresol should have smaller resonance energies and acidities than $m$-cresol.

I wish to thank several of my colleagues for preparing and certifying the samples of the phenols, and Messrs R. F. L. Andon and H. A. Gundry for their work on the calorimetric measurements.

\section{References}

${ }^{1}$ J. D. Cox, A. R. Challoner and A. R. Meetham. 7. Chem. Soc., 1954, 265

2 A. R. Challoner, H. A. Gundry and A. R. Meetham. Phil. Trans. Roy. Soc. London, 247, 553 (1955)

${ }^{3}$ J. D. Cox and H. A. Gundry. F. Chem. Soc., 1958, 1019

4 G. S. Parks, K. E. Manchester and L. M. Vaughan. F. Chem. Phys., 22, 2089 (1954)

5 F. D. Rossini, D. D. Wagman, W. H. Evans, S. Levine and I. Jaffe. "Selected values of chemical thermodynamic properties", Nat. Bur. Standards (U.S.) Circ. No. 500 (1952)

6 D. P. Biddiscombe and J. F. Martin. Trans. Faraday Soc., 54, 1316 (1958)

7 G. E. Coates and L. E. Sutton. 7. Chem. Soc., 1948, 1187

${ }^{8}$ F. Klages. Chem. Ber., 82, 358 (1949)

- K. J. Laidler. Can. F. Chem., 34, 626 (1956)

10 G. W. Wheland. Resonance in Organic Chemistry, pp. 106, 107, 342, Wiley, New York (1955)

11 J. S. Roberts and H. A. Skinner. Trans. Faraday Soc., 44, 339 (1949)

12 E. F. Herington and G. W. Kynaston. Trans. Faraday Soc., 53, 138 (1956) 